\title{
PENGARUH JENIS MINERAL LEMPUNG TERHADAP KUALITAS GENTENG KERAMIK
}

\author{
Taslimah, Wibisono, Sriyanti, Rum Hastuti \\ Laboratorium Kimia Jurusan Kimia \\ F MIPA Universitas Diponegoro Semarang 50275
}

\begin{abstract}
ABSTRAK
Telah dilakukan penentuan jenis mineral dan komposisi kimia bahan baku genteng Soka Kebumen dan Mateseh Kendal serta uji sifat fisik genteng dari bahan baku tersebut. Analisis dilakukan dengan metoda difraksi sinar- $X$ dan spektrofotomrter serapan atom, uji sifat fisik genteng meliputi susut kering, susut bakar, kuat tekan dan peresapa air. Disimpulkan bahwa lempung Soka Kebumen terdiri dari monmorionit, kaolinit, anortit dan kwarsa sedang lempung Mateseh Kendal terdiri dari haloisit dan anortit. Jenis mineral lempung yang berbeda menghasilkan kualitas genteng yang berbeda. Genteng Soka Kebumen dengan campuran pasir kualitasnya paling baik.
\end{abstract}

Kata kunci : mineral, genteng, kualitas.

\section{ABSTRACT}

Determination of the chemical and mineral constituent of Soka Kebumen and Mateseh Kendal clay has been done by atomic absorption spectrofotometer and X-ray diffraction method. The physical characteristic test on the roof tile include dry contraction, burning contraction, pressure test and water absorption. It was concluded that the mineral constituent of Soka Kebumen clay were monmorillonit, kaolinit, quars and anorthite and the constituent of Mateseh Kendal clay were haloisit and anorthite. The quality of roof tile determinated by the mineral constituent of clay, the best quality of roof tile is Soka Kebumen by sand adding.

Key word ; mineral, roof tile, quality

\section{PENDAHULUAN}

Genteng merupakan salah satu jenis material yang penting dalam pembangunan rumah-rumah atau gedung perkantoran. Pada umumnya pembuatan genteng keramik masih bersifat tradisional yang dibuat dalam skala industri rumah tangga dengan menggunakan bahan baku lempung. Kualitas genteng dari satu tempat dengan tempat lain sering tidak sama sehingga sering genteng dari satu daerah lebih terkenal dibanding dari tempat lain.Genteng yang baik harus memenuhi persyaratanpersyaratan tertentu antara lain kekuatan dan sifat peresapan airnya.

Sifat-sifat genteng sangat dipengaruhi oleh cara pembuatan dan bahan baku yang digunakan sedangkan sifat bahan baku ditentukan oleh sifat-sifat dari mineral komponen penyusunnya. Cara pembuatan genteng di suatu daerah kemungkinan berbeda dengan daerah lain, kemungkinan didaerah tertentu perlu dilakukan perlakuan-perlakuan tambahan dengan tujuan untuk memperbaiki sifat-sifat produk genteng yang dihasilkan.

Genteng soka dari Kebumen telah dikenal kualitasnya cukup baik oleh masyarakat secara luas dibanding genteng dari Mateseh Kendal sehingga pemasarannya meluas, mengingat Kendal letaknya lebih dekat dengan pantai dibanding Kebumen diduga perbedaan kualitas genteng yang dihasilkan disebabkan oleh perbedaan jenis bahan baku yang digunakan, karenanya untuk memperoleh sifat-sifat genteng yang baik dari bahan baku yang kualitasnya kurang perlu dilakukan modifikasi pada pembuatannya. Kualitas genteng ditetapkan berdasarkan standar SII 0022-81.

Dalam penelitian ini akan dikaji pengaruh jenis bahan baku lempung terhadap kualitas genteng Soka dari Kebumen dan genteng dari Mateseh Kendal.

\section{BAHAN DAN ALAT}

Bahan yang digunakan meliputi lempung dari Kebumen dan Kendal, pasir, asam fluorida, asam sulfat, asamnitrat asam perkloratlitium boron oksida, akuades. Peralatan yang digunakan meliputi ayakan, lumping agat, krus Teflon, furnace, spektrofotometer serapan atom Hitachi Polarized Zeemen, difraktometersinar-X tipe PW 3710 BASED dan peralatan gelas.

\section{METODA PENELITIAN}

Karakterisasi lempung dilakukan dengan difraktometer sinar- $\mathrm{X}$, analisis kimia lempung dilakukan dengan spektrofotometer serapan atom . 
Pembuatan sampel genteng dari bahan baku lempung Kebumen dan Kendal secara tradisional. Uji yang dilakukan terhadap sampel genteng sesuai dengan standar pengujian menurut standar industri Indonesia meliputi susut kering, susut bakar, kuat tekan dan peresapan air.

\section{Uji susut kering. (\%)}

Sampel yang telah dicetak dikeringkan satu hari di tempat yang teduh, kemudian dipindahkan pada tempat yang panas selama satu hari, setelah kering diukur panjangnya.

\begin{tabular}{|c|} 
susut kering $=\frac{a-b}{a} \quad$ X $100 \%$ \\
$\begin{aligned} a=\text { panjang mula-m ula } \\
b=\text { panjang setelah kering }\end{aligned}$
\end{tabular}

Uji susut bakar (\%).

Sampel yang telah kering dibakar pada tungku pembakar pada suhu sekitar $900-1000^{\circ} \mathrm{C}$ selama $12 \mathrm{jam}$, kemudian didinginkan selanjutnya diukur panjangnya.

$\begin{aligned} \text { susut bakar } & =\frac{\mathrm{b}-\mathrm{c}}{\mathrm{b}} \times 100 \% \\ \mathrm{~b} & =\text { panjang pada saatkering } \\ \mathrm{c} & =\text { panjang setelah dibakar }\end{aligned}$

\section{Uji kuat tekan}

Genteng yang telah dibakar diuji kekuatannya dengan memberi beban menggunakan mesin hidrolik hingga genteng pecah.

\section{Uji peresapan air(\%).}

Sampel genteng direbus dalam air mendidih selama 2 jam setelah dingin genteng diangkat di lap dan ditimbang

\begin{tabular}{|} 
peresapan air $=\frac{A-B}{B} \times 100 \%$ \\
$A=$ beratgenteng sebelum dicelup \\
B $=$ berat genting setelah dicelup
\end{tabular}

\section{HASIL DAN PEMBAHASAN}

Tanah lempung biasanya merupakan campuran dari lempung dan komponen non lempung, sedangkan sifatsifat lempung ditentukan oleh sifat-sifat mineral komponen penyusun lempung. Jenis mineral komponen penyusun lempung Soka Kebumen dan lempung Mateseh
Kendal ditentukan dengan difraktometer sinar-X, difraktogram yang dihasilkan disajikan pada gambar 1 .

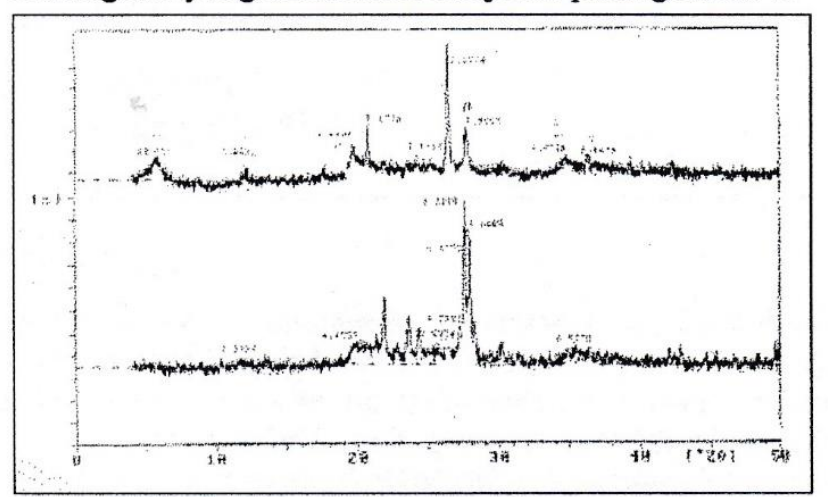

Gambar 1. difraktogram :

a. lempung Soka Kebumen

b. lempung Mateseh Kendal

Berdasarkan harga d dari puncak-puncak difraktogram dan penelusuran data ASTM, puncak-puncak tersebut dapat dikelompokkan sesuai dengan mineral-mineral berikut:

Tabel 1. Komposisi mineral sampel tanah lempung.

\begin{tabular}{|l|l|}
\hline \multicolumn{1}{|c|}{ Asal tanah lempung } & \multicolumn{1}{c|}{ Jenis mineral } \\
\hline Soka Kebumen & $\begin{array}{l}\text { Kwarsa,Kaolinit, Monmori- } \\
\text { lonit dan anortit } \\
\text { Anortit dan haloisit }\end{array}$ \\
Mateseh Kendal & . \\
\hline
\end{tabular}

Kwarsa dan anortit adalah mineral bukan komponen penyusun lempung, berdasarkan hasil analisis tersebut maka dapat dinyatakan bahwa jenis Lempung dari Soka Kebumen yang terdiri dari mineral kaolinit dan monmorilonit berbeda dengan jenis lempung dari Mateseh Kendal yang hanya mengandung mineral haloisit. Adanya perbedaan jenis mineral komponen penyusun lempung akan memberikan sifat yang berbeda dari kedua macam lempung karena struktur dari masing-masing mineral berbeda, sedangkan hasil analisis kimia kedua jenis sampel disajikan pada tabel 2

Tabel 2. Komposisi kimia sampel tanah lempung

\begin{tabular}{|c|c|c|}
\hline Oksida unsur & $\begin{array}{c}\text { Lempung Soka } \\
\text { Kebumen } \\
\text { Kadar (\%) }\end{array}$ & $\begin{array}{c}\text { Lempung } \\
\text { Mateseh Kendal } \\
\text { Kadar (\%) }\end{array}$ \\
\hline $\mathrm{SiO} 2$ & 63,54 & 65,13 \\
$\mathrm{Al} 2 \mathrm{O} 3$ & 14,06 & 14,94 \\
$\mathrm{CaO}$ & 0,96 & 1,79 \\
$\mathrm{Na2O}$ & 0,97 & 2,17 \\
$\mathrm{Fe} 2 \mathrm{O} 3$ & 6,309 & 6,89 \\
$\mathrm{MgO}$ & 2,216 & 0,913 \\
$\mathrm{~K} 2 \mathrm{O}$ & 1,266 & 0,972 \\
\hline
\end{tabular}

Kadar oksida-oksida pada tabel di atas tidak hanya berasal dari lempung saja tetapi merupakan total oksida yang ada baik dari komponen lempung maupun non lempung dari bahan baku tanah lempung, misal $\mathrm{SiO}_{2}$ 
adalah berasal dari lempung dan kwarsa bebas. Adanya komponen non lempung tersebut juga akan mempengaruhi sifat fisik seperti peresapan air dan plastisitas dari bahan baku.

Pada pembuatan genteng kualitas produk yang dihasilkan dipengaruhi oleh bahan baku, proses pembuatan dan pembakarannya. Dalam penelitian ini proses pembuatan dan pembakaran dilakukan bersama-sama untuk memperkecil kesalahan akibat proses pembuatan dan pembakaran sehingga ruang lingkup pembahasan difokuskan pada bahan baku saja dengan mengasumsikan proses pembuatan dan pembakaran berlangsung dengan baik atau mendekati sempurna. Pada pembuatan sampel genteng dilakukan dengan dantanpa penambahan pasir, hal ini dilakukan sebagai upaya untuk memperbaiki sifat sifat genteng seperti meningkatkan kemampuan genteng menahan air agar genteng tidak rembes bila terkena air hujan. Uji sifat fisik yang dilakukan terhadap genteng meliputi susut kering, susut bakar, kuat tekan dan peresapan air disajikan pada tabel 3 Tabel 3. Hasil uji sifat fisik genteng Soka Kebumen dan Mateseh Kendal

\begin{tabular}{|c|c|c|c|c|}
\hline Kode & $\begin{array}{c}\text { Susut } \\
\text { kering } \\
(\%)\end{array}$ & $\begin{array}{c}\text { Susut } \\
\text { bakar } \\
(\%)\end{array}$ & $\begin{array}{c}\text { Kuat tekan } \\
\text { (kg/cm2) }\end{array}$ & $\begin{array}{c}\text { Peresapan } \\
\text { air (\%) }\end{array}$ \\
\hline A1 & 11,42 & 0,974 & 28,2 & 9,0 \\
\hline A2 & 10,33 & 1,04 & 65 & 10,87 \\
\hline B1 & 8,80 & 0,95 & 61,9 & 19,1 \\
\hline B2 & 7,29 & 0,90 & 45,35 & 21,82 \\
\hline $\begin{array}{c}\text { Menurut } \\
\text { SII } \\
0022-81\end{array}$ & $\begin{array}{c}\text { Maks. } \\
10 \%\end{array}$ & $\begin{array}{c}\text { Maks. } \\
2 \%\end{array}$ & $\begin{array}{c}\text { Min. 20 } \\
\mathrm{kg} / \mathrm{cm} 2\end{array}$ & Maks. 20\% \\
\hline
\end{tabular}

A1 : genteng Soka Kebumen tanpa pasir.

B1 : genteng Mateseh Kendal tanpa pasir

A2 : genteng Soka Kebumen dengan pasir.

B2 : genteng Mateseh Kendal dengan pasir

Dari penampakan fisik, genteng Soka Kebumen mempunyai permukaan lebih halus dibandingkan genteng Mateseh Kendal. Dari hasil uji di atas susut kering maupun susut bakar genteng Soka Kebumen tanpa maupun dengan pasir mempunyai nilai yang lebih besar dari genting Mateseh Kendal, hal ini menunjukkan bahwa bahan baku lempung dari Kebumen lebih bersifat plastis dari pada bahan baku lempung dari Kendal, keadaan tersebut sesuai dengan fakta bahwa mineral penyusun lempung Soka Kebumen yang mengandung monmorilonit, mineral ini mempunyai struktur berlapis dimana molekul-molekul air dapat menempati ruang antar lapis sehinga lempung akan me- ngembang bila direndam dalam air, demikian juga mineral kaolinit dapat menyerap air meskipun kemampuan menyerap airnya lebih rendah dari monmorilonit akibatnya genteng yang dihasilkan mempunai susut kering dan susut bakar yang lebih besar. Susut kering juga dipengaruhi oleh besarnya kandungan oksida-oksida bebas seperti kwarsa, alumina dan lain-lain, adanya oksida-oksida bebas akan mengurangi besarnya susut kerinc maupun susut bakar dari genteng yang dibuat. Ditinjau dari kandungan oksida alkali lempung dari Mateseh Kendal terutama kandungan $\mathrm{Na}_{2} \mathrm{O}$-nya lebih tinggi. Jika $\mathrm{Na}$ hanya berasal dari lempung saja, maka sifat plastisnya akan lebih besar dari tanah lempung Soka Kebumen, namun dari uji susut kering maupun susut bakar nilainya lebih rendah berarti tanah lempung Mateseh Kendal plastisitasnya lebih rendah sehingga dapat dinyatakan bahwa $\mathrm{Na}_{2} \mathrm{O}$ yang ada tidak hanya berasal dari lempung saja. Mengingat Kendal letaknya relatif dekat dengan laut diduga $\mathrm{Na}$ berasal dari perembesan air laut yang membentuk senyawa yang dapat mengendap bersama lempung.

Susut kering atau susut bakar yang besar akan mempengaruhi kemampuan benda uji untuk menerima beban, lempung yang plastis akan mengalami penyusutan volume yang besar pada pengeringan dan pembakaran sehingga permukaannya mudah retak akibatnya bila dikenai beban akan mudah pecah .

Genteng Soka mempunyai peresapan air yang rendah dibanding genteng Mateseh hal ini berkaitan dengan jenis mineral penyusun lempung, lempung Soka terdiri dari mineral monmorilonit dan kaolinit yang mempunyai ukuran butir yang halus sehingga genteng yang dihasilkan mempunyai kerapatan yang besar dan permukaannya halus karenanya air sukar masuk sedang mineral lempung Mateseh mempunyai ukuran butir yang lebih besar sehingga genteng yang dihasilkan kerapatannya rendah, dapat terbentuk ruang antar butir dan permukaannya lebih kasar sehingga air dapat memasuki ruang antar butir akibatnya perembesannya besar.

Genteng yang baik harus mempunyai kekuatan yang tinggi dan peresapan air yang rendah agar kuat menerima beban dan tidak rembes bila hujan, berdasarkan hal ini genteng Soka peresapannya baik tetapi kekuatannya sangat rendah sedangka genteng Mateseh sebaliknya. Untuk memperbaiki sifat genteng diiakukan 
pembuatan genteng dengan menambahkan pasir, penambahan pasir ini akan berdampak pada penyusutan volume akibat pengeringan maupun pembakaran menjadi kecil, permukaan genteng menjadil tidak mudah retak, akibatnya kekuatan genteng Soka meningkat banyak meskipun peresapan airnya juga meningkat, namun meningkatnya peresapan air relatif kecil sehingga masih memennuhi standar mutu yang telah ditentukan menurut SII 0022-81

Pada genteng Mateseh dengan campuran pasir menyebabkan kuat tekannya menurun dan peresapan airnya meningkat hal ini terjadi karena pasir mempunyai ukuran butir yang lebih besar dari ukuran butir haloisit karenanya penambahan pasir justru akan memperbesar ruang antar butir sehingga air yang dapat mengisi ruang tersebut makin banyak. Secara umum dapat dinyatakan bahwa pembuatan genteng Mateseh Kendal tidak perlu ditambahkan pasir, sedang pembuatan genteng Soka Kebumen perlu ditambahkan pasir. Dari keempat jenis genteng yang dibuat genteng Soka Kebumen dengan tambahan pasir adalah yang paling baik kualitasnya.

\section{KESIMPULAN}

Berdasarkan pembahasan di atas dapat disimpulkan sebagai berikut :
1. Mineral komponen penyusun tanah lempung dari Soka Kebumen adalah monmorilonit, kaolinit, kwarsa dan anortit sedang tanah lempung dari Mateseh Kendal terdiri dari haloisit dan anortit

2. Perbedaan jenis mineral komponen penyusun lempung akan menghasilkan kualitas genteng yang berbeda.

3. Dari keempat jenis genteng yang dibuat Genteng Soka Kebumen dengan campuran pasir adalah yang paling baik kualitasnya..

\section{PUSTAKA}

1. Hartomo, Y.M.V., 1988; “ Hasil Uji Produk Industi Bata Genteng Skala Kecil di Jawa" Kumpulan Karya Ilmiah, Balai Besar Keramik Bandung.

2. Tan, K. H., 1982; "Principles of Soil Chemistry" Published Marcel Dekker, New York.

3. Namara, E.P., 1948; "Introduction to Ceramic" The Pensylvinia State College.

4. Eysberg., 1978; "Fundamentals of Modern Physics" Wiley Published, New York.

5. SII 0022-81 "Genteng Keramik" Depperind.

6. Richmeyer, E.H., Kennard dan Copper, J.M., 1969; "Introduction to Modern Physics" 6nd ed. Mc. Grow hill, New York. 